\title{
BREVES REFLEXÕES SOBRE A \\ COMUNICAÇÃO E ESTADO DEMOCRÁTICO
}

COMMUNICATION AND DEMOCRATIC STATE:

SOME REFLECTIONS

\begin{abstract}
Marialva Carlos Barbosa
Doutorado em História pela Universidade Federal Fluminense, Brasil(1996). Pós-Doutorado pelo Centre National des Recherches Scientifiques, França(1999).

Atuação em Jornalismo e Editoração, com ênfase em Jornalismo Especializado

(Comunitário, Rural, Empresarial, Científico).

Professor Titular da Universidade Federal Fluminense, Brasil
\end{abstract}

\section{RESUMO}

O texto produz amplas reflexões sobre a questão do Estado a partir da teoria de Estado Ampliado de Gramsci, procurando mostrar que enxergar a política como catarse pode ser um bom exercício teórico no sentido de considerar as complexas relações históricas no que diz respeito à questão da dominação.

Palavras-chave: Estado; Gramsci; política

\section{ABSTRACT}

The text makes extensive reflections on the question of the State from the theory of State Enlarged Gramsci, trying to show that see politics as catharsis may be a good theoretical exercise to consider the complex historical relationships with respect to the question of domination.

Keywords: State; Gramsci; politics

Esse texto é produto de uma reflexão pontual realizada II Encontro de Pesquisa em Comunicação e Cidadania, realizado entre os dias $11 \mathrm{e}$ 13 de novembro de 2008, organizado pelo Programa de Pós-Graduação em Comunicação da Universidade Federal de Goiás (UFG) e pelo Núcleo de Pesquisa em Comunicação e Cidadania da Universidade Católica de Goiás (SER). Naquela oportunidade, tive o prazer de debater com o conferencista que abriu o evento, Murilo César Ramos, um especialista na questão das relações sempre conflituosas com o Estado, quando se trata do projeto de construir um projeto democrático para os meios de comunicação. Esse Estado demiúrgico, entendido num primeiro momento como governo e numa pequena extensão como 
poder político.

Não sendo uma especialista nas relações comunicação e política, sendo quase uma neófita no assunto, não fosse a sólida formação em história que me acompanha, pouco teria a dizer sobre um tema tão complexo e sobre o qual inúmeros especialistas na área de comunicação vêm se debruçando com afinco.

Portanto, a minha intervenção naquela noite se referiu pontualmente à questão política, a partir de um autor fundamental para a formulação de uma teoria em torno do Estado, Antonio Gramsci. Procurei mostrar também que a crise política apontada muitas vezes como algo próprio da contemporaneidade atravessa a história brasileira. Caracterizando-se como um lugar no qual a mistura entre o público e o privado torna-se a gênese dessa política, no qual o compadrio e os favores e favorecimentos eram (ou são?) o padrão dominante, a prática política no país foi construída pela prevalência dos interesses dos dominantes e pela ação no sentido da exacerbação da dominação.

Numa sociedade escravista, na qual a palavra de ordem era a palavra do açoite, as distinções entre quem possuía de fato o poder de voz e aqueles que não possuíam sequer rostos, sempre foram muito acentuadas. Nem o ingresso do país nas muitas novas repúblicas que construiu ao longo da sua história, nem a pretensão de que vivemos uma pretensa "pós-modernidade" dominada pelo dinamismo ofertado pelas tecnologias sempre novas de comunicação possibilitou o término dessas desigualdades sociais gritantes que impedem a entrada do país num novo patamar histórico, governado pela força da inclusão e não da exclusão social.

Portanto, essa exposição centrase em três focos principais: a necessidade de pensar historicamente os processos sociais, inserindo nessa reflexão a questão das formações históricas específicas; pensar a política enquanto operador teórico que forneça elementos para refletir sobre as práticas construídas historicamente no Brasil; e, finalmente, visualizar sempre a possibilidade de criação de artimanhas cotidianas construídas pelos sujeitos históricos, que produzem astúcias mesmo quando submetidos a mais contundente dominação.

Astúcias que, muitas vezes encobertas na história, se desvelam com a história. Pouca gente sabe, por exemplo, que muitos dos escravos que habitam as cidades e os campos no século XIX, quando aqui vivíamos o mais miserável sistema de exploração da humanidade, ou seja, a escravidão, eram detentores de uma cultura letrada que foi envolvida pelo véu do esquecimento. Leitores ou imersos no mundo do letramento eram capazes de ler, escrever, contar, cantar e contar histórias, dominando o universo cultural da oralidade e das práticas da leitura, da escrita, enfim o mundo cognitivo do letramento. Por que então esse silêncio histórico? Por que não se revela que os escravos eram também leitores de primeira, de segunda e de terceira natureza? Por que não interessa mostrar que eram capazes de saber o que os periódicos diziam a seu respeito, por ouvir dizer, por que um outro lia para eles aquelas notícias ou por que eram capazes de decifrar os impressos? Silêncios históricos sobre o mundo do conhecimento dos escravos que reafirmam uma domina 
ção de natureza também histórica.

As suas astúcias também são silenciadas. $\mathrm{O}$ fato de usar os códigos do mundo do letramento - se fazendo passar por outros, encobrindo o nome e desvelando outros nomes, entre diversas outras artimanhas para produzir astúcias, táticas difusas que materializam resistências, não faz parte de um conhecimento que deve ser descortinado.

Como afirma Agnes Heller (1993), o conhecimento é sempre relativo ao momento histórico em que se vive. Em diferentes momentos da história, ou em idades anteriores, como ela conceitua, sempre houve coisas que um mortal não deveria saber e, portanto, não poderiam ser pensadas ou interpretadas à luz da produção do conhecimento pelos teóricos daquele tempo. Esse conhecimento podia ser considerado, por exemplo, demoníaco ou uma forma de transgressão moral. O conhecimento é um valor que possui as possibilidades das épocas históricas em que se vive. A história, comoafirma Dilthey, é a autobiografia de pessoas e da humanidade. Da mesma forma que cotidianamente reescrevemos a história de nossas vidas, a humanidade reescreve novamente sua biografia (Heller, 1993, p. 107).

Esse conhecimento sobre o mundo dos escravos e sobre a escravidão é seguidamente silenciado, como também é pouco reconhecido o poder de criação dos sujeitos históricos que nas artimanhas cotidianas realizam atos de resistências às múltiplas dominações. Assim, ao lado do poder dos dominantes devemos começar a prestar a atenção na ação dos dominados. Nesse sentido, pensar a política como catar- se, tal como concebeu Gramsci, talvez nos ajude a descentralizar nosso olhar e a perceber que essa catarse se realiza nas ações mais simples da vida.

\section{Um Estado em relação}

Pode parecer uma incongruência trazer o pensamento de Gramsci para pensar as práticas cotidianas. Mas não o é.

Gramsci concebeu sempre o mundo em relação, as práticas como ações e o papel ativo do sujeito não apenas na compreensão de si mesmo, mas do mundo a sua volta. Ainda que um mundo envelopado predominantemente pela ação da política. E não podia ser diferente. Escrevemos sempre sobre o que nos atormenta, o que não conseguimos compreender. A ação de escrever descortina no pensamento aquilo que não somos capazes de explicar.

Vivendo num mundo dilacerado pelos totalitarismos, pela ação irracional do ser humano, materializado nas dominações do fascismo, sofrendo diretamente na carne as consequências das ações irracionais daqueles que pretendiam lançar seus tentáculos para dominar, pelo totalitarismo, corações e mentes, Gramsci, um pensador completo, se debruça sobre questões que afetavam diretamente aqueles que viam na liberdade e na prática humana a única possibilidade de transformação e que, naquele momento histórico, estavam irremediavelmente amordaçados.

No Cárcere, onde ficou por onze longos anos e de onde saiu para morrer, produziu em pequenos cadernos de anotação sua densa Teoria 
Ampliada de Estado. Acreditando na força da ação humana, tentou compreender o seu tempo produzindo uma complexa teorização que coloca no centro da reflexão a ação política do sujeito.

Ainda que tenha pensado um Estado, que mesmo produto de relações sociais, continuava lançando seus múltiplos tentáculos sobre o indivíduo, sob a forma de coerção ou tentando pela via das incontáveis possibilidades discursivas produzir o consenso nos aparelhos privados de hegemonia (escola, família, igreja e imprensa, entre outros), Gramsci procurou mostrar que, só através da ação humana, se poderia pensar em mudar qualquer realidade.

O sujeito ativo, participante, produtor de significados, que constrói sua história ao viver a existência, é, portanto, o alvo prioritário do pensamento do teórico italiano. Assim, o Estado não poderia ser apenas uma entidade a serviço das classes ou dos grupos, o Estado Objeto. Não poderia também ser visto como alguma coisa dotada de poder imanente, entidade autônoma, deslocada das relações sociais e históricas, o Estado Sujeito. Para Gramsci o Estado se constituía em relação, estava na relação, era uma relação de natureza social, e sobre o qual dever-se-ia pensar na ação e nas práticas de sujeitos reais.

Por isso concebeu que para efetuar suas ações, nas relações sociais, havia que se considerar não apenas a força natural de quem tem as ferramentas coercitivas para produzir a dominação. Era preciso pensar que, muitas vezes, os dominantes produzem o consentimento dos dominados não exclusivamente pela força real, mas por uma outra força, simbólica, no qual os discursos emitidos desempenham fundamental tarefa. Fazer prevalecer como dominante uma visão por toda a sociedade e fazer com que essa visão ecoe na boca dos dominados como suas visões de mundo é uma tarefa que necessita mais do que coerção. É preciso produzir a sensação do consenso e isso se faria, na sua concepção, através dos chamados aparelhos privados de hegemonia.

O Estado Ampliado de Gramsci, portanto, pressupunha a existência de uma sociedade política (o Governo) e de uma sociedade civil, na qual se localizariam os aparelhos privados de hegemonia. Essas duas esferas agindo em relação na sociedade real, habitada por sujeitos culturais reais e que existiam nas materialidades de suas vidas cotidianas, produziam o Estado Ampliado.

Gramsci produziu uma teoria na qual a questão da ação humana era central. Através da cultura dos grupos que ocupam o lugar dos dominados poder-se-ia transformar, com a força da ação, o mundo em que se vivia e inverter a lógica da dominação. Daí a importância da escola, dos lugares de produção do lazer dos operários nas fábricas, dos jornais (meio de comunicação possível no seu tempo). Esses aparelhos privados de hegemonia poderiam ser usados para a transformação do mundo, fazendo com que outros grupos ocupassem, nessa relação de força, o lugar dos dominantes. Viver, para Gramsci, era uma questão de luta por hegemonia.

A produção enunciativa tem, portanto, papel chave nessa transformação. Pela educação, pelo teatro, pela força da palavra que ensina, educa e projeta visões de mundo encontrar-se-ia a chave para mudar 
a praxis como lugar da libertação e da unidade humana, via na ação do sujeito a possibilidade do desenvolvimento da ação política. Política que para ele tinha um sentido suplementar muito além do sentido restrito, isto é, conjunto de práticas e objetivações que se referem ao Estado e às relações de poder entre governantes e governados.

Quando o sujeito passa de "momento econômico para o momento ético-político", dizia Gramsci, quando consegue, em consciência, perceber que o lugar que ocupa é dos dominados e luta para transformar essa realidade, realiza um ato político, produz política. Passando do "objetivo ao subjetivo e da necessidade à liberdade" vive a cartarse.

São, portanto, as condições reais de existência que permitem aos sujeitos perceberem seu estado de sujeição no mundo. Quando a partir dessas condições, do objetivo, empreende ações no sentido da transformação (subjetivo), o homem passa da mera necessidade (de sobrevivência) às ações de transformação do mundo (à liberdade). Em uma palavra, vive a política como catarse.

Claro que o entendimento das condições históricas de dominação são fundamentais para a compreensão do fenômeno comunicacional numa formação histórica como o Brasil, demarcado por lutas políticas nas quais a questão da dominação se sobressai. Não devemos ser ingênuos e tomar a ação criativa do sujeito da dominação como possibilidade única de libertação, sem considerar as condições reais de sua existência. Mas, por outro lado, não podemos pensar que o sujeito da sujeição está irremediavelmente perdido entre as amarras dos dominantes, sem possibilidade de construir significados para a sua existência. Nem tanto ao mar, nem tanto à terra.

Portanto, do ponto de vista dos estudos de comunicação o pensamento de Antonio Gramsci e a questão do Estado Ampliado tornase fundamental para a compreensão dos múltiplos processosmultifacetados que envolvem a relação da imprensa e dos meios de comunicação nas sociedades contemporâneas.

Num momento de complexidade das relações sociais e simbólicas, os meios de comunicação não apenas criam as necessidades do público, como instauram modos de apreensão da realidade social, constituindo-a, de tal forma, que se torna um Estado dentro do Estado. Os meios de comunicação como um partido político elabora a violência simbólica, instaura os gostos e anseios, descortina o real e simboliza os mitos. Além da questão da publicização do mundo para o leitor - exercendo uma função de constituição da realidade - os meios de comunicação se transformam numa espécie de essência do mundo contemporâneo.

Há de se considerar também o papel exercido pelos profissionais midiáticos (jornalistas, num primeiro instante, e em outros nomes profissionais, imersos em muito na complexidade dos processos comunicacionais) na formulação das idéias dominantes no Brasil e na construção de pensamentos hegemônicos em muitos momentos históricos.

A própria passagem de sociedade Oriental à Ocidental, no sentido gramsciniano dos termos, não pode prescindir da ação da imprensa que cunhou os epítetos 
da modernização e instauração um progresso compulsório para o país. Se num primeiro momento, isto é, na passagem da Monarquia para a República, a ação da imprensa foi fundamental para construir a idéia desse progresso, como passagem do atraso para a civilização, no Estado Novo também, as relações da sociedade política com os aparelhos privados de hegemonia, representados, sobretudo, pela imprensa, foram fundamentais para o desmonte do operariado como grupo reivindicador e para a construção de um sindicalismo de estado. Os jornais desempenham, neste momento, papel fundamental na ampliação do discurso estadonovista e na construção ideológica do regime. $\mathrm{O}$ aliancismo que se observa naquele momento com a sociedade política faz dos jornalistas, muitos dos quais claramente cooptados pelo poder, mais uma vez porta-vozes dos grupos dominantes, sendo que alguns passarão a ser intelectuais orgânicos dos grupos dirigentes.

Também em outro período de exceção na história mais recente do país - os governos ditatoriais militares - a ação dos meios de comunicação é fundamental para construir um outro ideal de modernidade e possibilitar o que Gramsci chama a prática do transformismo. O Estado substitui os grupos sociais na função de dirigir uma luta de renovação. $\mathrm{E}$ a imprensa, como parte integrante desse estado e como partido dos grupos dominantes e hegemônicos, difundirá mais uma vez a mítica da modernidade como indispensável para a construção de uma nova face para o país, inserido numa fase do capitalismo mundial. Mesmo que isso tenha significado o silêncio dos meios de comunicação com relação à censura, às torturas e às práticas disseminadas de exceção.

A transição para o capitalismo no Brasil de fato se fez "pelo alto", inserida dentro do que Gramsci chama revolução passiva, isto é, a ausência de uma iniciativa popular unitária, o que faz com que as classes dominantes reajam a essas ações de forma esporádica e desorganizada. Neste momento, os dominantes acolhem uma parcela das exigências provenientes desses grupos, instaurando uma "revolução passiva".

No momento atual, quando se observa uma das mais contundentes crises hegemônicas da história do país, também os meios de comunicação desempenham papel fundamental: ampliando e tornando visível a crise se constroem mais uma vez como porta-vozes legítimos da sociedade, ampliando o seu poder real e simbólico.

Portanto, mais uma vez a imprensa materializa o Estado, desta vez procurando dar voz às forças contra-hegemônicas, tornando públicas suas simbologia e ideologia políticas, narrando suas ações, midiatizando-as, criando contextos para a sua descrição, enfim, referendando convenções que passam a ser interpretadas de uma ou de outra forma.

Transpor a teoria da hegemonia para os meios de comunicação não significa apenas importar as categorias de Marx, Lênin e Gramsci para um universo recoberto pelo discurso ideológico. É preciso não esquecer que quando se fala em comunicação, fala-se também de um caráter simbólico, de uma linguagem (indissociável desse caráter). Assim, é preciso ver a relação comunicacional na sua dimensão política, incluindo o simbolismo dos sentidos 
criam e seus efeitos imaginários.

Mas dominação também se faz quando não se reconhece que os homens são capazes de nos atos mais corriqueiros expressar a sua ação no mundo e a sua consciência. Há que pensar que mesmo sendo objeto de múltiplas sujeições, o ser histórico reage, nos limites de suas possibilidades também históricas, às imposições. Muitas vezes de forma incompreensível aos nossos olhos, outras tantas de uma forma diferente da que gostaríamos.

Algumas vezes, achamos que as nossas concepções de mundo, a maneira como vivemos e pensamos o mundo deve ser espraiada por toda a sociedade. Que a nossa noção de Democracia é a única possível, que a Verdade que postulamos é a única desejada. Formas de ação que também escondem o ato dominador. Os conceitos e as possibilidades que o saber pretensamente instaura são também formas de engendrar um

\section{Referências}

COUTINHO, Carlos Nelson e NOGUEIRA, Marco Aurélio (org). Gramsci e a América Latina. Rio de Janeiro: Paz e Terra, 1988.

COUTINHO, Carlos Nelson. Gramsci. Um estudo sobre seu pensamento político. Rio de Janeiro: Civilização Brasileira, 2003.

DE CERTEAU, Michel. A invenção do cotidiano. As artes de fazer I. Petrópolis: Vozes, 2000.

GRAMSCI, Antonio. Maquiavel, a política e o estado moderno. Rio de Janeiro: Civilização Brasileira, 1991.

HELLER, Agnes. Uma teoria da história. Rio de Janeiro: Brasiliense, 1993.

MENDONÇA, Sonia Regina e BARBOSA, Marialva Carlos. Estado e Comunicação no Brasil: em torno do pensamento de Antonio Gramsci. In: CD Rom do IV Encontro Nacional da Rede Alfredo de Carvalho. São Luis, 2006. 